\title{
Comparison of the value of passive safety coefficients for car crash with lighting column made of aluminum or composite material based on numerical simulation
}

\author{
Wojciech Danek ${ }^{1, *}$, and Damian Gąsiorek ${ }^{2}$ \\ ${ }^{1}$ Silesian University of Technology, Institute of Theoretical and Applied Mechanics, Konarskiego \\ 18A, Gliwice, Poland \\ ${ }^{2}$ Silesian University of Technology, Institute of Theoretical and Applied Mechanics, Konarskiego \\ 18A, Gliwice, Poland
}

\begin{abstract}
Numerical simulations have become more and more important in recent years for the design of supporting road equipment structures. These structures are important for ensuring the proper level of passive safety for drivers and passengers. These structures also allow the reduction of costs of entry for new products on the market and reduction of the total cost of production. In this paper was shown comparison of passive safety coefficient ASI and THIV for lighting column made of composite material and aluminum based on experimentally verified numerical simulation. FEM was used to carry out the simulation which was implemented in LS Dyna to determine passive safety coefficients, whose algorithm was written in MATLAB. Authors presented parameters of numerical model of the car and lighting column with the ground. The accepted boundary and initial conditions were chosen in order to show the behaviour of the lighting column during a collision with a car.
\end{abstract}

\section{Introduction}

A modern trend for design elements included in road infrastructure is assurance of maximum safety for drivers and passengers. For this purpose, each newly designed infrastructural element is subject to a series of numerical analyses whose purposes are to determine properties of the element during the impact by the vehicle. As a result, the effect of the passive safety of passengers is determined. The results of the numerical simulations are verified by experimental studies. Based on the data presented in a report by the Polish police in 2017, there were nearly 33,000 traffic accidents, in which 3,000 people were killed. A significant proportion of these accidents were collisions with all sorts of obstacles in the forms of trees and lighting columns. In order to increase the passive safety of passengers, in the case of lighting columns, various efforts have been used to significantly reduce strength overload, which arises at the moment of impact, below a level dangerous to

* Corresponding author: wojciech.danek@polsl.pl 
humans. research related to this issue was the subject of earlier work carried out by the author [1-2]. Issues related to the research regarding lighting columns are the subject of numerous scientific publications. These publications encompass experiments and virtual tests carried out in various computing environments [3-5]

Supporting road equipment structures like lighting columns can, during a collision, constitute a threat to drivers and passengers. Therefore, when this element of road equipment is designed, one should seek to increase passive safety for drivers and passengers. For this purpose, European standard EN 12767 distinguishes three categories of passive safety [6]:

- High energy absorbing (HE),

- Low energy absorbing (LE),

- Non-energy absorbing (NE).

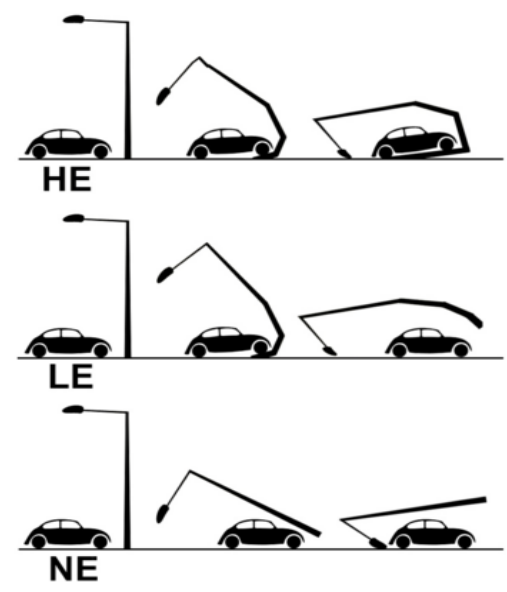

Fig. 1. Level of energy absorption according to EN 12767.

Constructions qualified as HE class are intended to significantly reduce the car's velocity and to reduce the risk of crashes with another car or with other elements of road infrastructure. Lighting columns qualify within two classes are intended to reduce the car's velocity with low risk of significant damage to health.

In order to determine to which class of passive safety a particular construction will be qualified, there are two types of coefficients: Acceleration Severity Index (ASI) and Theoretical Head Impact Velocity (THIV). ASI allows determination of a nuisance motion of the vehicle for people sitting near selected measuring points (usually a center of gravity). It is considered a determinant of accident severity to passengers in the vehicle upon impact with an obstacle. It is determined from the dependence shown below [7-9]:

$$
A S I(t)=\left[(\bar{a} x / \hat{a} x)^{2}+(\bar{a} y / \hat{a} y)^{2}+(\bar{a} z / \hat{a} z)^{2}\right]^{1 / 2}
$$

Where:

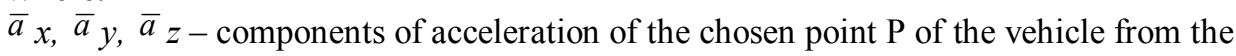
movable averaged time interval $\delta=50 \mathrm{~ms}$,

$\hat{a}_{x}, \hat{a}_{y}, \hat{a}_{z}-$ limit value of acceleration along $\mathrm{X}, \mathrm{Y}, \mathrm{Z}$ axes of the vehicle.

For passengers using seat belts, limit values of acceleration are equal to:

- $\hat{a}_{x}=12 \mathrm{~g}$,

- $\hat{a}_{y}=9 \mathrm{~g}$,

- $\hat{a}_{z}=10 \mathrm{~g}$, 
Theoretical Head Impact Velocity is the velocity of the head during an impact the surface inside the vehicle and is determined from the dependence shown below [7-9]:

$$
\text { THIV }=\left[\mathrm{V}_{\mathrm{x}}^{2}(\mathrm{~T})+\mathrm{V}_{\mathrm{y}}^{2}(\mathrm{~T})\right]^{1 / 2}
$$

Where:

$V_{x}(T), V_{y}(T)$ - velocity of theoretical head at the time of impact in the surface inside the vehicle.

Values of these two coefficients are determined for different velocities depending on the road where this obstacle is located.

\section{Numerical model}

Numerical simulations were performed using a numerical model of Suzuki Swift which met requirements related to mass of the vehicle and center of gravity contained in the standard EN 12767 [6]. Due to the complicated construction of the vehicle and incomplete information about the parameters of the elements included in the vehicle, a model made by the National Crash Analysis Center (NCAC) was used in the simulation. The data relating the parameters of mass and geometry to the elements that have been used for the discretization of the model are shown in Table 1.

Table 1. Geometric parameters of the vehicle and division on finite elements

\begin{tabular}{|c|c|}
\hline Vehicle weight [kg] & 860 \\
\hline Wheel base [mm] & 2371 \\
\hline Distance the center of mass from the front axle [mm] & 1128 \\
\hline Number of nodes & 19271 \\
\hline Number of solid elements & 820 \\
\hline Number of beam elements & 4 \\
\hline Number of shell elements & 15330 \\
\hline Total number of finite elements & 16154 \\
\hline Number of parts & 242 \\
\hline Number of material models & 6 \\
\hline
\end{tabular}

The lighting column with its inspection door were modelled as shell elements for which the wall thickness was set as specified by the manufacturer. The data relating the parameters of mass and geometry to the elements that have been used for the discretization of the model are shown in Table 2. Presented data are in accordance with standards [10-12]

Table 2. Geometric parameters of the lighting column and division on finite elements

\begin{tabular}{|c|c|}
\hline Height of the lighting column [m] & 7 \\
\hline Thickness of the wall of the lighting column [mm] & 4 \\
\hline Net Weight column [kg] & 40 \\
\hline Composite & 65 \\
\hline aluminum & 593897 \\
\hline Dimensions of the ground & 430775 \\
\hline Number of nodes & 87121 \\
\hline Number of solid elements & 4 \\
\hline Number of shell elements & \\
\hline Number of material models & \\
\hline
\end{tabular}

In the case of modeling the lighting column, it was decided to include ground for the model, whose dimensions were determined from the European standard EN 12767. It was 
decided to model the assembly of the lighting column this way in order to reflect the real conditions at the time of impact with a vehicle.

As a model for the material of the lighting column made of aluminum "Material Model 24: Piecewise Linear Isotropic Plasticity" while for construction made of composite material "Material Model 054 Enhanced Composite Damage" were chosen. Parameters for the composite material and aluminum was determined based on experimental research made on MTS Criterion Model 43 was chosen. Parameters for ground material model was taken from literature [13]

As a model for the material of the ground "Material Model 05: Soil And Foam"

Additional conditions related to displacements of individual elements and velocity were imposed on the system. In the case of conditions related to displacements, all degrees of freedom were removed in the nodes located on the outer walls of the ground. Linear velocity equal 35 and $50 \mathrm{~km} / \mathrm{h}$ [7-9] was determined for all nodes of the car and angular velocity was determined for wheels. Additionally, in order for the conditions to be as close to reality as possible during the simulation, the gravitational force acted in the system.

\section{Results of numerical simulations}

In this chapter results of numerical simulation was shown. Numerical simulation model was verified by experiment for car crash with composite lighting column, where value of $r$ Person correlation coefficient was equal 0,724. Results of Passive Safety coefficient ASI for aluminum and composite material were shown on Fig. 2.

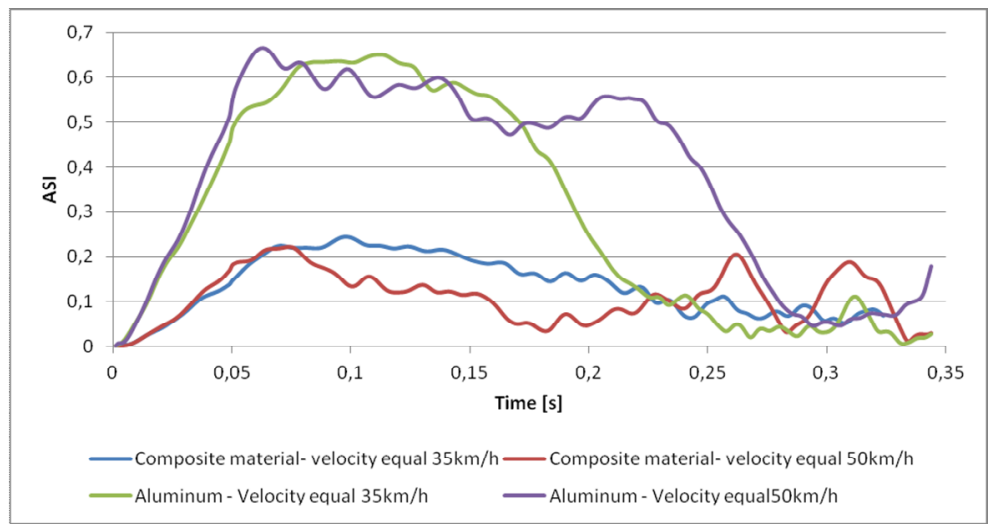

Fig. 2. Values of ASI coefficient for aluminum and composite material lighting column during crash.

Second Passive Safety coefficient THIV for lighting column was equal:

-For Composite material - velocity equal $35 \mathrm{~km} / \mathrm{h}-32,1 \mathrm{~km} / \mathrm{h}$

-For Composite material - velocity equal $50 \mathrm{~km} / \mathrm{h}-39,6 \mathrm{~km} / \mathrm{h}$

-For Aluminum material - velocity equal $35 \mathrm{~km} / \mathrm{h}-24,6 \mathrm{~km} / \mathrm{h}$

-For Aluminum material - velocity equal $50 \mathrm{~km} / \mathrm{h}-29,2 \mathrm{~km} / \mathrm{h}$

Based on result obtained from numerical simulation can be observed that construction made of aluminium are characterized by higher value of passive safety coefficient ASI. Value of this coefficient for lighting column made of aluminium is almost three times higher than for lighting column made of composite material. In case of second passive safety coefficient THIV can be observed that construction made of aluminum are characterized by lower value of this coefficient than construction made of composite material. Qualitive analysis for every presented simulations was shown on Fig. 3. 

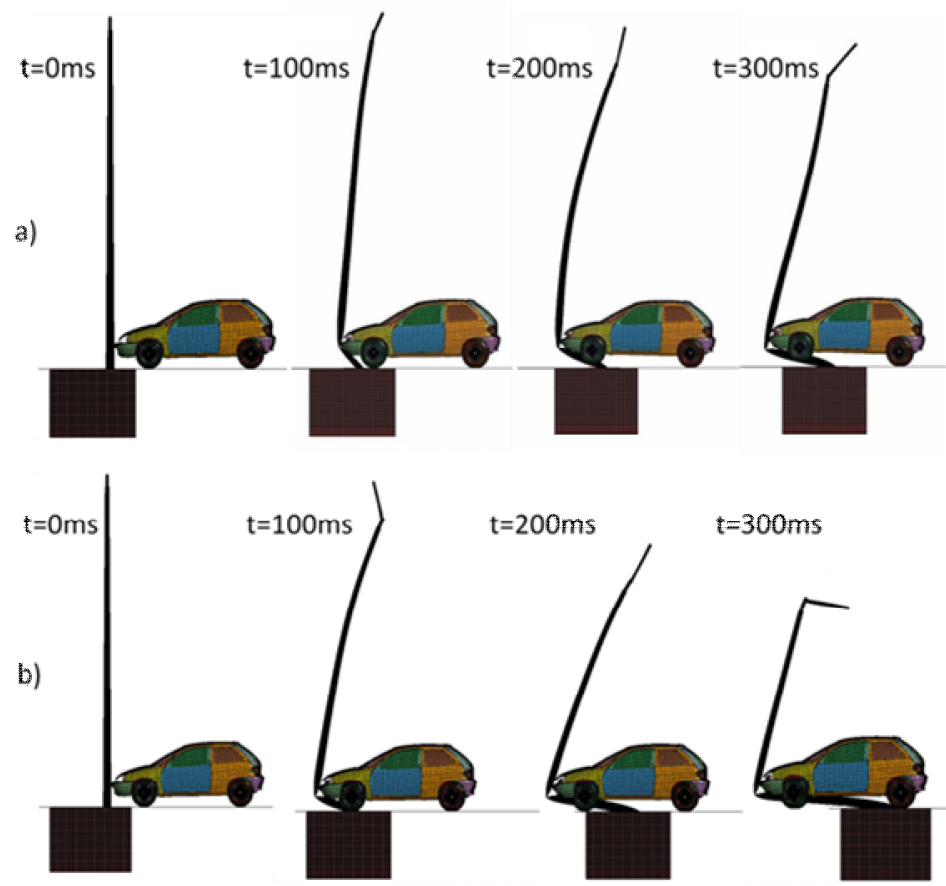

$=300 \mathrm{~ms}$
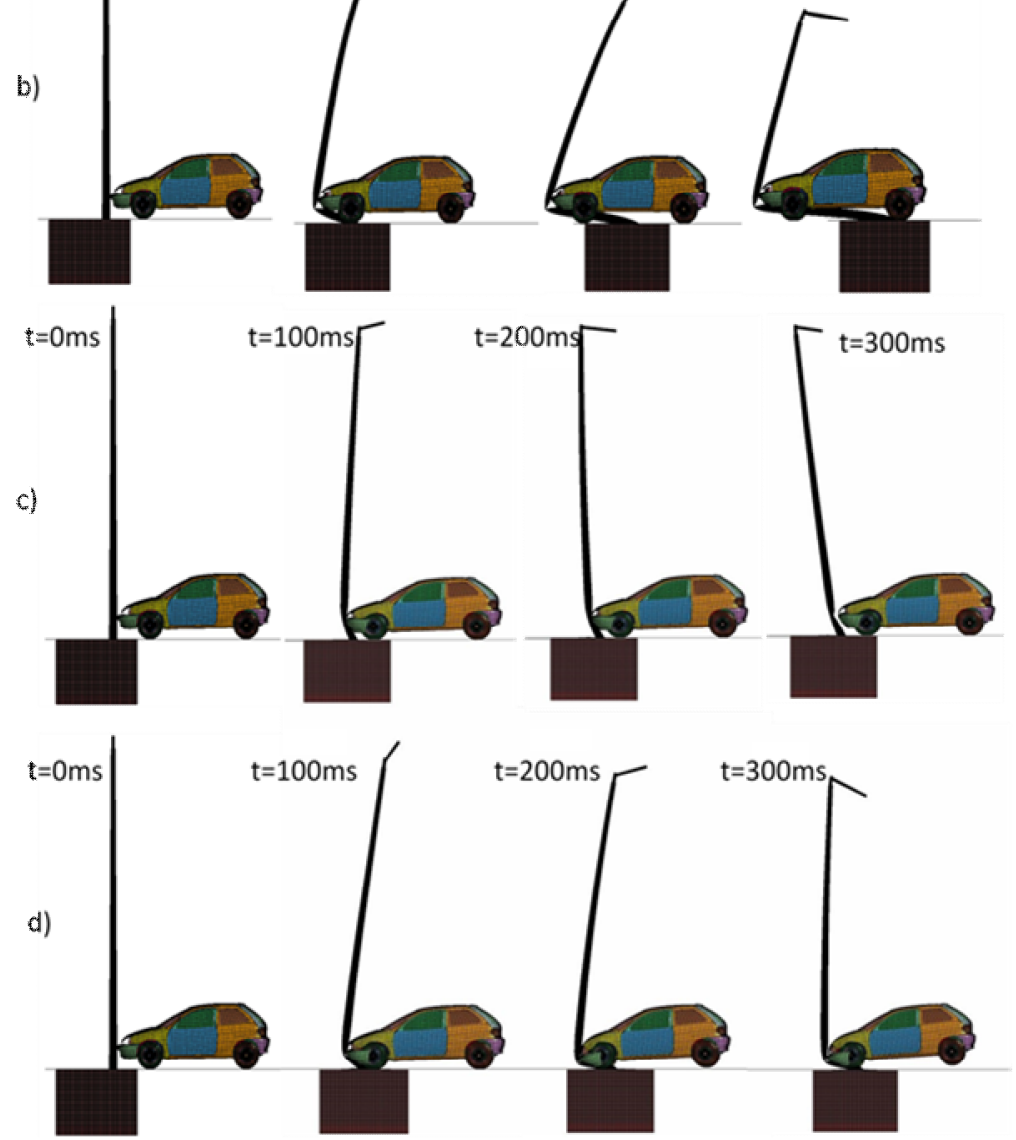

Fig. 3. Qualitative analysis of a collision with lighting column: a) Composite material - velocity $35 \mathrm{~km} / \mathrm{h}$, b) Composite material - velocity $50 \mathrm{~km} / \mathrm{h}$, c) Aluminum material - velocity $35 \mathrm{~km} / \mathrm{h}$, d) Aluminum material - velocity $35 \mathrm{~km} / \mathrm{h}$.

Based on the results shown on Fig. 3 can be observed that construction made of aluminum absorb more kinetic energy during the collision than construction made of composite material. 


\section{Summary}

Based on the result obtained from numerical simulation passive safety coefficients ASI and THIV was determined. For lighting column made of aluminum was observed that value of ASI coefficient is almost three times higher than for the lighting column made of composite material. For second passive safety coefficient THIV for lighting column made of aluminum this coefficient is lower than for construction made of composite material. Presented in this work Qualitative analysis shown that construction made of aluminum absorb more kinetic energy during collision than lighting column made of composite material. Future work will be done on this model to optimize the shape of the lighting column in order to reduce the values of the passive safety coefficients.

\section{References}

1. W. Danek, M. Pawlak, Springer Proceedings in Mathematics \& Statistics: Dynamical Systems in Applications, 249, 73-84 (2018)

2. W. Danek, D. Gąsiorek, Modelowanie Inżynierskie, 66, 25-30 (2018)

3. M. Pawlak, Mechanics Research Communications, 77, 21-28 (2016)

4. Y. Abdel-Nasser, J. Alrajhi, M. Alardhi, K. Alkhulaifi, International Journal of Traffic and Transportation Engineering, 2(5), 101-105 (2013)

5. G. Janszen, Safety and Security Engineering, II, 347-355 (2007)

6. European Committee for Standardization, EN 12767 Passive safety of support structures for road equipment -Requirements and test methods. Draft proposal of revised EN 12767. 2005-06-02. 30p.28

7. European Committee for Standardization, SFS-EN 1317-1 Road Restraint Systems, Part 1: Terminology and General Criteria for Test Methods, Edita Oyj,Helsinki, 1998

8. European Committee for Standardization, SFS-EN 1317-2 Road Restraint Systems, Part 2: Performance Classes, Impact Test Acceptance Criteria and Test Methods for Safety Barriers, Edita Oyj, Helsinki, 1998

9. European Committee for Standardization, SFS-EN 1317-3 Road Restraint Systems, Part 3: Performance Classes, Impact Test Acceptance Criteria and Test Methods for Crash Cushions, Edita Oyj, Helsinki, 2001

10. European Committee for Standardization, SFS-EN 40-3-1 Lighting Columns, Part 3-1: Design and Verification-Specification for Characteristic Loads, Edita Oyj, Helsinki, 2000

11. European Committee for Standardization, SS-EN 40-3-2 Design and verification Verification by testing, Svensk Standard, 2013

12. European Committee for Standardization, SFS-EN- 40-3-3 Lighting Columns-Part 33: Design and Verification-Verification by Calculation, Finnish Standards Association, Helsinki, 2004

13. E. Fasanella, K. Jackson, NASA Langley Research Center (2009) 